\title{
Association of Hyponatremia and Encephalopathy in Patients with Chronic Liver Disease
}

\author{
Muhammad Akbar Memon, ${ }^{1}$ Nadeem Memom, ${ }^{2}$ Abdul Qadir, ${ }^{3}$ Abdul Salam Dal ${ }^{4}$
}

\section{Abstract}

Objective: To determine the association of hyponatremia in chronic liver disease patients with presentation of hepatic encephalopathy (HE) at Isra university Hospital Hyderabad.

Methods: This study was cross sectional and carried out at medicine and gastroenterology department of Isra university Hospital Hyderabad and MMC MirpurKhas. Study duration was from September 2015 to March 2016. All the cases with age more than 25 years, both genders after diagnosis of chronic liver disease with sign and symptoms of Hepatic Encephalopathy were selected in this study. Blood sample for serum sodium level, was send to diagnostic laboratory of the hospital. Hyponatremia was classified as: 130$135 \mathrm{mEqL}$ (mild), 125-130 $\mathrm{mEq} / \mathrm{L}$ (moderate) and $<125 \mathrm{mEq} / \mathrm{L}$ (severe). Hepatic encephalopathy was categorized according to the West Haven classifi-

\footnotetext{
${ }^{1}$ Assistant Professor, Medicine Department of Isra University Hospital, Hyderabad.

${ }^{2}$ Assistant Professor, Medicine Department of MMC, Mirpurkhas.

${ }^{3}$ Assistant Professor, Medicine Department of MMC, Mirpurkhas.

${ }^{4}$ Consultant General Physician, Liaquat University Hospital, Hyderabad.
}

\section{Date of Submission: 30-06-2016}

Date of $1^{\text {st }}$ Revision Received: 27-08-2016

Date of $2^{\text {nd }}$ Revision Received: 27-12-2016

Date of Acceptance for publication: 15-01-2017

Conflict of Interest: None

Funding Source: None

\section{Contribution}

All Authors have contributed in Study Design, Data Collection, Data Analysis, Data Interpretation, Manuscript Writing and Approval. cation (4 grades)

Results: Total number of cases was 80 . Mean age was $48+8.5$ years. $55(68.5 \%)$ patients were male. Majority of cases, $55(68.5 \%)$ patients were infected with HCV. $40 \%$ patients had normal level of sodium, $25 \%$ had mild, $20 \%$ had moderate while $15 \%$ patients had severe hyponatremia. On the grading of encephalopathy, $30(37.5 \%)$ patients had grade 1 encephalopathy while $25 /(31.2 \%)$ patients had grade $2,15 /(18.8 \%)$ had grade 3 while $10(12.5 \%)$ patients hade grade 4 . The serum sodium levels significantly decreased with increasing severity of hepatic encephalopathy $(\mathrm{P}=$ 0.001).

Conclusion: We concluded that the hyponatremia is significantly linked with Hepatic Encephalopathy (HE) in patients having chronic liver disease (CLD).

Key Words: CLD, hyponatremia, hepatic encephalopathy.

\section{Introduction}

Chronic liver diseases (CLD) and its complications are the major health problem, due to big burden of Hepatitis $\mathrm{C}$ virus and Hepatitis B virus in the community ${ }^{1}$ and it is also the commonest reason of death in Pakistani population. It is very common reason of admission to our hospitals. ${ }^{2}$ In the decompensation condition, cases having CLD generally present with ascites, jaundice, portal hypertension, gastrointestinal hemorrhage, spontaneous bacterial peritonitis and hepatic encephalopathy. ${ }^{3}$ About $30 \%$ of patients with CLD usually die due to Porto systemic encephalopathy. ${ }^{4}$ The clinical course of patients with CLD is frequently complicated due to increase in the renal function abnormalities and imbalance of electrolytes. ${ }^{5}$

In the body disturbance of the water is the main sign of advance cirrhosis, ${ }^{6}$ This phenomena of distur- 
bance of water is linked to the existence of ascites and is characterized by the development of dilutional hyponatremia, which is a frequent complication and sequel of chronic liver disease. ${ }^{5,7}$ Recent study indicates that hyponatremia is a key prognostic factor in patients with CLD. ${ }^{8}$ The prevalence of hyponatremia [serum $\mathrm{Na}<130 \mathrm{mEq} / \mathrm{L}$ ] in patients with cirrhosis with ascites is approximately $30 \% .^{9}$ The relationship between hyponatremia and severity of cirrhosis is associated with the development of complications. hepatic encephalopathy, hepatorenal syndrome and spontaneous bacterial peritonitis are more presented in cases having serum concentration $<130 \mathrm{mEq} .{ }^{10}$ Furthermore in cases having ascites, those having hyponatremia have a lower diuretics response, higher frequency of refractory ascites, and frequent requirement of the therapeutic paracentesis. ${ }^{11}$ A study from Pakistan demonstrated $51.6 \%$ of CLD cases had serum sodium concentration below than the normal level. ${ }^{5}$ Borroni et al, ${ }^{12}$ reported that hyponatremia was in $30 \%$ of CLD cases. Hyponatremia can induce or aggravate Hepatic encephalopathy, leading to disease progression like seizures, coma and even brain death. The aim of this study was to evaluate the association of hyponatremia in chronic liver disease patients with presentation of hepatic encephalopathy.

\section{Material and Methods}

This study was cross sectional and carried out at medicine and gastroenterology department of Isra university Hospital Hyderabad and MMC Mirpur Khas. Study duration was 7 months from September 2015 to March 2016. All the cases with age more than 25 years, both genders, after diagnosis of chronic liver disease with sign and symptoms of hepatic encephalopathy were selected in this study. All the cases on diuretic therapy, with hepatocellular carcinoma, with diabetes, hypertension (HTN), heart failure and chronic kidney disease (CKD) were excluded from the study. Detailed history, clinical examination and various routine and necessary investigations were done in all cases. After that blood sample for serum sodium level, was sent to diagnostic laboratory of the hospital. The demographic profile of the patients was noted. The severity of decrease sodium concentration was assessed as normal serum sodium $[\mathrm{Na}+]$ level is 135 $145 \mathrm{mmol} / \mathrm{L}$ and the value $<135$ was labeled as low or hyponatremia. The severity of hyponatremia was categorized as: $130-135 \mathrm{mEqL}$ (mild), $125-130 \mathrm{mEq} / \mathrm{L}$ (moderate) and $<125 \mathrm{mEq} / \mathrm{L}$ (severe). The hepatic encephalopathy was graded according to the West Haven classification (4 grades). Grades I-II were taken as mild to moderate encephalopathy, while grades IIIIV were taken as severe encephalopathy. All the data regarding age, gender, serum sodium concentration, presence of hepatic encephalopathy were recorded. All the data were entered into SPSS 16.0 version and were analyzed by using the same software.

\section{Results}

Total number of cases was 80 . Mean age was $48+8.5$ years. Males were found in the majority as compared to females. Regarding virology status of cases, HCV patients were most common, 10 patients had HBV while 15 patients were infected by both $\mathrm{HCV}$ and HBV (Table 1).

Table 1: Basic characteristic of cases $(n=80)$.
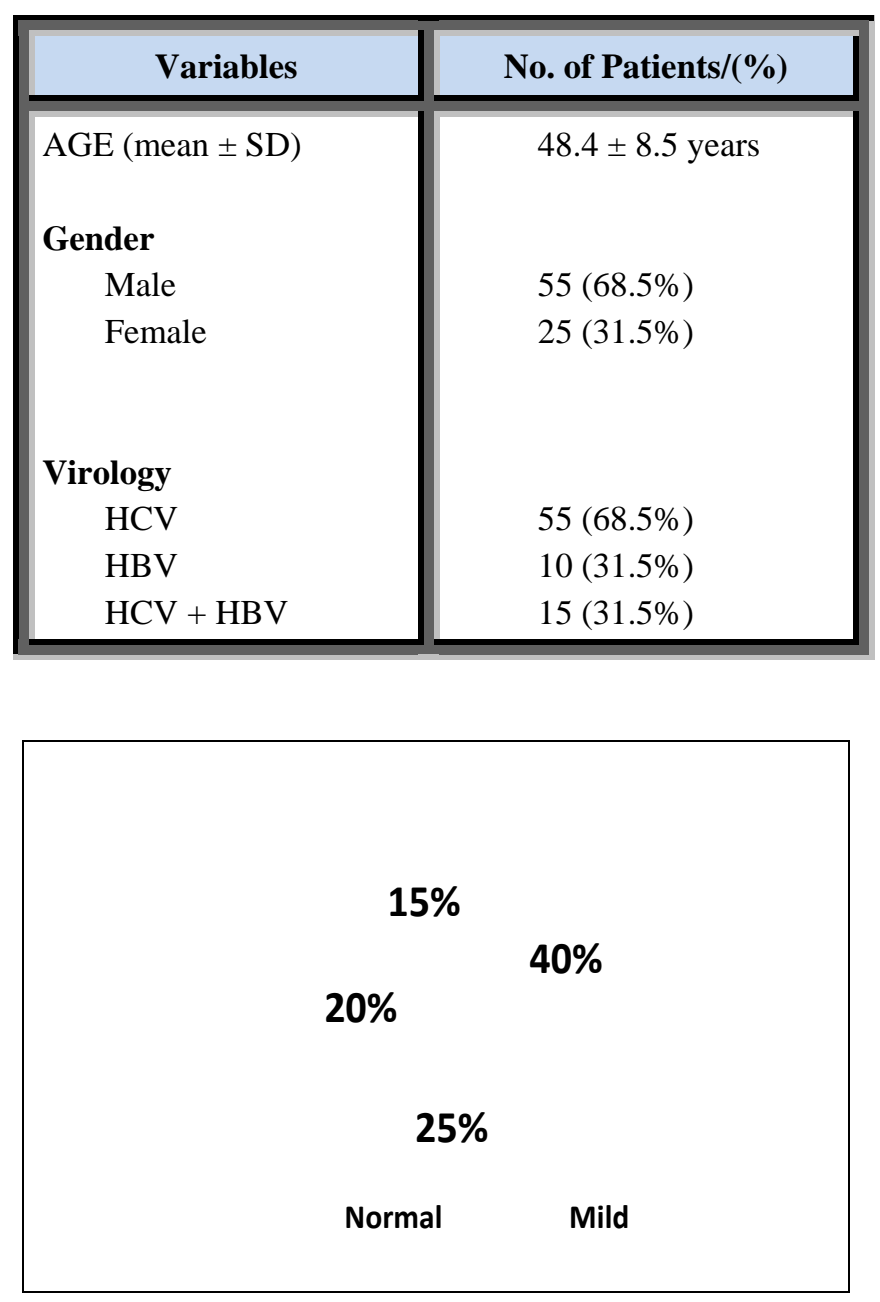

Fig. 1: Hyponatremia Classification $n=80$. 
According to classification of hyponatremia, majority of the patients had normal level of sodium, $25 \%$ had mild, $20 \%$ had moderate while $15 \%$ patients had severe hyponatremia (Fig. 1).

On the grading of encephalopathy, mostly patients were found with grade 1 encephalopathy while 25 patients had grade 2, 15 patients had grade 3 while 10 patients hade grade 4 encephalopathy (Fig. 2).

In the results of this study serum sodium level significantly decreased with increasing the severity of hepatic encephalopathy $p=$ value 0.001 (Table 3.)

\section{Discussion}

Hepatic encephalopathy (HE) is commonest and serious complications of cirrhosis and is also the main reason of mortality. ${ }^{13}$ Hyponatremia can induce or aggravate $\mathrm{HE}$, leading to disease progression and even death. ${ }^{14,15}$ In this study total number of cases was 80 . Mean age was $48 \pm 8.5$ years. 55 $(68.5 \%)$ patients were male while 25 (31.5\%) patients were female. Similarly Qureshi MA et al. ${ }^{16}$ reported that of 202 patients, $90(44.6 \%)$ were males and $112(55.4 \%)$ females. Eighty-one $(40.1 \%)$ patients were of the age greater than 60 years. Sulehria SB etal. ${ }^{17}$ reported that common age was recorded $44.56 \pm 3.63$ years, 172 $(68.8 \%)$ were male and $78(31.2 \%)$ were female.

In this study $40 \%$ patients had normal level of sodium, $25 \%$ had mild, $20 \%$ had moderate while $15 \%$ patients had severe hyponatremia. As well as Sulehria SB et al. ${ }^{17}$ reported that $129(51.6 \%)$ patients had hyponatremia due to chronic liver disease, while $121(48.4 \%)$ had no hyponatremia. In a Korean study ${ }^{18}$ prevalence of hyponatremia (less than serum sodium $\leq 135 \mathrm{mmol} / \mathrm{L}$ ) was $47.9 \%$ in hospitalized patients.

The hyponatremia sodium $(\leq 130 \mathrm{mmol} / \mathrm{L}$ was $27) .1 \%$. In this series on the grading of encephalopathy, $30(37.5 \%)$ patients had grade 1 encephalopathy while $25 /(31.2 \%)$ patients had grade 2,15 $(18.8 \%)$ had grade 3 while $10(12.5 \%)$ patients hade grade 4 encephalopathy. Sulehria SB et al. ${ }^{17}$ reported that out of 129 patients with hyponatraemia, 16 (12.4\%) were having grade I, 24 (18.6\%) had grade II, 38 (9.46\%) had grade III and 51 (39.54\%) had grade IV hepatic encephalopathy.

In the results of this study decreases of serum sodium level is very important in CLD and its severity
Table 2: Grading of Hepatic Encephalopathy $(n=80)$.

\begin{tabular}{|l|c||c|}
\hline Variables & No. of patients & \% \\
\hline Grade: I & 30 & $37.5 \%$ \\
Grade: II & 25 & $12.5 \%$ \\
Grade: III & 15 & $18.8 \%$ \\
Grade: IV & 10 & $31.2 \%$ \\
\hline
\end{tabular}

Hyponatremia According to Severity of Hepatic Encephalopathy $(n=80)$.

Grade: I

Grade: II

Grade: III

Grade: IV

$=$ value 0.001 by applying the chi-square test
Severity of Hyponatremia

\begin{tabular}{|c|c|c||c||}
\hline $\begin{array}{c}\text { Normal } \\
\mathbf{N = 3 2}\end{array}$ & $\begin{array}{c}\text { Mild } \\
\mathbf{N = 2 0}\end{array}$ & $\begin{array}{c}\text { Moderate } \\
\mathbf{N = 1 6}\end{array}$ & $\begin{array}{c}\text { Severe } \\
\mathbf{N = 1 2}\end{array}$ \\
\hline \hline 20 & 07 & 03 & 00 \\
11 & 08 & 05 & 01 \\
01 & 04 & 05 & 05 \\
00 & 01 & 03 & 06 \\
\hline
\end{tabular}

is significantly associated with severity of hepatic encephalopathy $\mathrm{p}=$ value 0.001 . Similarly Samiullah Shaikh et al. ${ }^{19}$ stated that the greater frequency of hyponatremia was seen in patients having hepatic encephalopathy. In another study, the severity of hyponatremia, particularly at sodium level $\leq 130 \mathrm{mmol} / \mathrm{L}$, corresponded to increase the risks of ascites, hepatic encephalopathy and other complications of cirrhosis, as compared those with the serum sodium level $\leq 136$ $\mathrm{mmol} / \mathrm{L} .^{15,20}$

Association between HE and serum sodium levels may be described as; severe liver failure in cases with level of serum sodium $<130 \mathrm{meq} / \mathrm{l}$, and these both events may be pathophysiologically associated. ${ }^{21}$ Decreased sodium level in cases having CLD, is associated with are mark able reduction of organic osmolytes in the cerebral concentration, that probably reflect compensatory osmo regulatory mechanisms against cell swelling. ${ }^{22,23}$

\section{Conclusion}

We concluded that the hyponatremia is significantly associated with hepatic encephalopathy in patients having chronic liver disease. Therefore it is recom- 
mended that every patient who presents with chronic liver disease should be investigated for hyponatremia to identify patients at high risk of complications including hepatic encephalopathy.

\section{References}

1. Nadeem MMA, Yousaf M, Zakaria T,Hussain N, Ali 2005. The value of clinical signs in diagnosis of cirrhosis. Pak. J. Med. Sci. 2005; 21: 121-4.

2. Almani SAAS, Memon AI, Memon I, Shah Q, Rahpoto R, Solangi, 2008. Cirrhosis of liver: Etiological factors, complications and prognosis. J. LiaquatUni Med Health Sci. 2008; 7: 61-6.

3. Khyalappa R, Bardeskar A. Significance of Hyponatremia in Decompensated Chronic Liver Diseases. Sch. J. App. Med. Sci. 2016; 4: 606-608.

4. Hayat AS, Shaikh N,Memon F. Identification of Precipitating Factors in Hepatic Encephalopathy Patients at Liaquat University Hospital Jamshoro. World Appl. Sci. J. 2010; 8 (6): 661-66.

5. Qureshi MO, Khokhar N, Saleem A, Niazi TK. Correlation of Hyponatremia with Hepatic Encephalopathy and Severity of Liver Disease. Journal of the College of Physicians and Surgeons Pakistan. 2014; 24 (2): 13537.

6. Ginès $\mathrm{P}$, Berl $\mathrm{T}$, Bernardi $\mathrm{M}$. Hyponatremia in cirrhosis: from pathogenesis to treatment. Hepatology. 1998; 28: 851-64.

7. Gaglio, MarfoK, Chiodo J. Hyponatremia in Cirrhosis and End-Stage Liver Disease: Treatment with the Vasopressin $\mathrm{V}_{2}$-Receptor Antagonist Tolvaptan. Dig Dis Sci. 2012; 57 (11): 2774-85.

8. Shaikh S, Mal G, Khalid S, Baloch GH, Akbar Y. Frequency of hyponatremia and its influence on liver cirrhosis-related complications. J Pak Med Assoc 2010; 60: 116-20.

9. Cárdenas A, Ginès P. Predicting mortality in cirrhosisserum sodium helps. N Engl J Med. 2008; 359: 1060-6.

10. Shaikh S, Mal G, Khalid SH, Baloch GH, Akbar Y. Frequency of hyponatraemia and its influence on liver cirrhosis - related complications. J Pak Med Assoc. 2010; 602: 116-120.

11. Bernardi M, Serena C, Santi L. Hyponatremia in Patients with Cirrhosis of the Liver. J. Clin. Med. 2015; 4: 85-101.
12. Borroni G, Maggi A, Sangiovanni A, Cazzaniga M, Salerno F. Clinical relevance of hyponatremia for the hospital outcome of cirrhotic patients. Dig Liver Dis. 2000; 32: 605-10.

13. Khokhar N, Niazi SA. Chronic liver disease related mortality pattern in Northern Pakistan. J Coll Physicians Surg Pak. 2003; 13: 495-7.

14. Li W, Shaoqi Y, Rui H, Jianguo H. Hyponatremia in patients with cirrhosis with hepatic encephalopathy [Internet]. [updated2011 Mar 17; cited 2011 Dec15]. Available from: http://www.hi128.com

15. Guevara M, Baccaro ME, Ríos J, Martín-Llahí M, Uriz J, Ruiz del Arbol L, et al. Risk factors for hepatic encephalopathy in patients with cirrhosis and refractory ascites: relevance of serum sodium concentration. Liver Int. 2010; 30: 1137-42.

16. Qureshi MO, Khokhar N, Saleem A, Niazi T K. Correlation of Hyponatremia with Hepatic Encephalopathy and Severity of Liver Disease. Journal of the College of Physicians and Surgeons Pakistan. 2014; 24 (2): 135137.

17. Sulehriasb, Zafar MS, Rauf, M, Ghafoor A. Frequency of Hyponatraemia in Hepatic Encephalopathy in Chronic Liver Disease at Mayo Hospital, Lahore. PJMHS. 2013; 4: 1204-6.

18. Borroni G, Maggi A, Sangiovanni A, Cazzaniga M, Salerno F. Clinical relevance of hyponatremia for the hospital outcome of cirrhotic patients. Dig Liver Dis. 2000; 32: 605-10.

19. Shaikh S, Mal G, Khalid S, Baloch GH, Akbar Y. Frequency of hyponatraemia and its influence on liver cirrhosis-related complications. J Pak Med Assoc. 2010; 60 (2): 116-20.

20. Cárdenas A, Ginès P. Predicting mortality in cirrhosisserum sodium helps. N Engl J Med.2008; 359: 1060-6.

21. Angeli P, Wong F, Watson H, Gines P. Hyponatremia in cirrhosis: results of a patient population survey. Hepatology. 2006; 44: 1535-42.

22. Restuccia T, Gomez-Anson B, Guevara M, Alessandria C, Torre A, Alayrach ME. Effects of dilutional hyponatremia on brain organic osmolytes and water content in patients with cirrhosis. Hepatology.2004; 39: 161322.

23. Ha ussinger D. Low grade cerebral edema and the pathogenesis of hepatic encephalopathy in cirrhosis. Hepatology. 2006; 43: 1187-90. 